\title{
Functionalized PHB granules provide the basis for the efficient side-chain cleavage of cholesterol and analogs in recombinant Bacillus megaterium
}

\author{
Adrian Gerber ${ }^{1}$, Michael Kleser ${ }^{1}$, Rebekka Biedendieck ${ }^{2}$, Rita Bernhardt ${ }^{1}$ and Frank Hannemann ${ }^{\text {** }}$
}

\begin{abstract}
Background: Cholesterol, the precursor of all steroid hormones, is the most abundant steroid in vertebrates and exhibits highly hydrophobic properties, rendering it a difficult substrate for aqueous microbial biotransformations. In the present study, we developed a Bacillus megaterium based whole-cell system that allows the side-chain cleavage of this sterol and investigated the underlying physiological basis of the biocatalysis.

Results: CYP11A1, the side-chain cleaving cytochrome P450, was recombinantly expressed in the Gram-positive soil bacterium $B$. megaterium combined with the required electron transfer proteins. By applying a mixture of 2-hydroxypropyl- $\beta$-cyclodextrin and Quillaja saponin as solubilizing agents, the zoosterols cholesterol and 7-dehydrocholesterol, as well as the phytosterol $\beta$-sitosterol could be efficiently converted to pregnenolone or 7-dehydropregnenolone. Fluorescence-microscopic analysis revealed that cholesterol accumulates in the carbon and energy storage-serving poly(3-hydroxybutyrate) (PHB) bodies and that the membrane proteins CYP11A1 and its redox partner adrenodoxin reductase (AdR) are likewise localized to their surrounding phospholipid/protein monolayer. The capacity to store cholesterol was absent in a mutant strain devoid of the PHB-producing polymerase subunit PhaC, resulting in a drastically decreased cholesterol conversion rate, while no effect on the expression of the recombinant proteins could be observed.

Conclusion: We established a whole-cell system based on B. megaterium, which enables the conversion of the steroid hormone precursor cholesterol to pregnenolone in substantial quantities. We demonstrate that the microorganism's PHB granules, aggregates of bioplastic coated with a protein/phospholipid monolayer, are crucial for the high conversion rate by serving as substrate storage. This microbial system opens the way for an industrial conversion of the abundantly available cholesterol to any type of steroid hormones, which represent one of the biggest groups of drugs for the treatment of a wide variety of diseases.
\end{abstract}

Keywords: Cholesterol, Cytochrome P450, Bacillus megaterium, Pregnenolone, PHB

\section{Background}

The chemical cleavage of a carbon-carbon bond is extremely difficult to execute, due to the inertness of these highly thermostable bonds and the constraint spatial properties of its $\sigma$-orbitals [1]. There are, however,

\footnotetext{
*Correspondence: f.hannemann@mx.uni-saarland.de

${ }^{1}$ Centre for Human and Molecular Biology, Institute of Biochemistry,

Saarland University, 66123 Saarbrücken, Germany

Full list of author information is available at the end of the article
}

several enzymes that can specifically catalyze this reaction type, a prime example being the cytochrome P450 $11 \mathrm{~A} 1$, which is able to cleave the non-activated sidechain of cholesterol [2], leading to pregnenolone, the central compound in the biogenesis of steroid hormones in all vertebrates. Its derivatives build a group of about 300 approved steroid drugs which are commonly used for the treatment of a variety of diseases since the 1950's [3]. For example, glucocorticoids are administered for 
the treatment of rheumatoid arthritis, asthma, eczema, anaphylactic shock, and Addison's disease; steroidal sex hormones for the treatment of male sexual organ dysfunction, gynecopathy and for contraception; and anabolic steroid hormones for the treatment of diuresis, sinusitis and the improvement of protein metabolism.

Owing to the great demand for steroidal drugs, the production developed steadily since Merck first introduced cortisone as a drug [4]. Today, the steroid production represents one of the largest sectors of medical products manufactured by the pharmaceutical industry and is one of the best examples of the successful combination of chemical and microbial technology in large scale industrial processes. Although some of the applied microbial conversions are well-established, efforts are ongoing either to improve the existing bioconversions or to develop new economically interesting processes such as the microbial side-chain cleavage of natural sterols to produce pregnenolone. The application of low-cost extracts of the most abundant sterol cholesterol or its plant-derived analogs as substrates has been hindered so far by the hydrophobic nature of these substances and, subsequently, their low uptake rate into microbial cells. Hence, to the best our knowledge, so far no recombinant whole-cell system has been described, which can efficiently convert these compounds to pregnenolone. Attempts to utilize recombinant E. coli for pregnenolone production yielded only product concentrations in the $\mu \mathrm{g} / \mathrm{L}$ range after $24 \mathrm{~h}$ [5]. In recent years, efforts have been made to produce steroid hormones in Saccharomyces cerevisiae by engineering the sterol biosynthesis pathway of the organism itself and thus endogenously providing the substrates for the recombinant enzymes [6-8]. However, this leads to the accumulation of unwanted side-products like ergosterol and brassicasterol that cannot be converted to pregnenolone [9] by CYP11A1, due to the presence of a double bond between carbon atoms 20 and 22 in the side-chain of these substrates, resulting in a reduced efficiency of the whole-cell system.

The selected host in this work, Bacillus megaterium, is an aerobic, Gram-positive bacterium, which is mostly found in soil. In the past two decades this non-pathogenic microorganism has gained attention as a host for biotechnological applications owing to its high capacity for recombinant protein production, high plasmid stability and broad range of substrates [10]. Additionally, its large cell size with a 100-fold higher volume compared to Escherichia coli cells allows detailed microscopic studies [11]. We constructed a B. megaterium strain that recombinantly produces bovine CYP11A1 and its redox partners adrenodoxin (Adx) and adrenodoxin reductase (AdR) [12].
CYP11A1 belongs to the large and diverse superfamily of P450 enzymes that act as external monooxygenases and catalyze a broad variety of reactions. They activate molecular oxygen through their heme iron and catalyze the oxidation of organic substances during biotransformation of xenobiotics, metabolic activation of carcinogens and biosynthesis of steroids [13, 14]. CYP11A1, as a mitochondrial P450 enzyme, receives the necessary electrons for catalysis from NADPH via a typical class I redox system [15], in which the [2Fe2S] ferredoxin Adx transfers electrons from an NADPH-dependent ferredoxin reductase, AdR, to the heme iron in CYP11A1. The terminal electron acceptor CYP11A1 takes up the waterinsoluble cholesterol at the inner mitochondrial membrane and converts it to the less hydrophobic product pregnenolone, removing the unpolar side chain by cleaving the 20,22 bond of the steroid. This reaction is mainly carried out in the male and female reproductive tissues and the adrenal gland and represents the first, rate-limiting and hormonally regulated step in the synthesis of all steroid hormones in mammals. Pregnenolone is the precursor of all glucocorticoids, mineralocorticoids, and steroidal sex hormones. In addition, pregnenolone serves as a neurosteroid, involved in memory and neurological recovery by promoting microtubule polymerization and cell migration [16]. CYP11A1 is also expressed in the human skin, forming a metabolically active barrier by activating or inactivating biologically relevant molecules. The enzyme transforms 7-dehydrocholesterol (7DHC), the precursor of vitamin D3, to 7-dehydropregnenolone (7DHP), whose photo-transformed 5,7-diene derivatives exhibit an anti-proliferative effect against melanoma and leukemia cells [17].

The efficient substrate conversion presented in this work is based on the presence of granules in the cytosol of B. megaterium [18-20], predominantly containing poly(3-hydroxybutyrate) (PHB), a form of polyhydroxyalkanoic acid (PHA). These natural water-insoluble inclusions are formed by various bacteria and serve as carbon and energy storage during times of oversupply with carbon sources. They are complex subcellular organelles consisting of a PHB core surrounded by a monolayer of phospholipids and essential proteins for PHA metabolism [21]. These proteins are responsible for the biosynthesis or the degradation of PHA and include subunits of the PHA synthase, phasins, PHA depolymerizing enzymes, and regulatory proteins [22, 23]. Among them, PHA synthase is the key enzyme of PHA synthesis. It accepts coenzyme A thioesters of hydroxyalkanoic acids (HA) as substrates and catalyzes the polymerization of HAs into PHA while simultaneously releasing CoA. PHA synthases currently are divided into four classes depending on their subunit composition and substrate 
specificity, whereas Bacillus sp. express dimeric class IV PHA synthases consisting of the subunits $\mathrm{PhaC}$ and PhaR, respectively.

Due to their interesting physical and material properties the polyesters derived from PHB granules are considered for several applications in medicine, pharmacy, agriculture as well as the packaging and food industry [24]. The granules have also attracted interest for the production of biocompatible and biodegradable nanoparticles, which can be applied for drug delivery, diagnostics, bioseparation and protein immobilization [25].

In the present paper, we are demonstrating the efficient in vivo conversion of cholesterol or analogs by a recombinant microorganism, utilizing the bacterium's PHB granules for substrate storage and embedding of the heterologous membrane proteins, without modifying these proteins with additional affinity tags. This biocatalyst system allows the production of the steroid precursor pregnenolone starting from low-cost crude extracts of cholesterol or plant-derived sterols like $\beta$-sitosterol or campesterol. After this crucial step, pregnenolone can further be transformed to a variety of desired endproducts either by chemical means or by the application of further steroid converting enzymes.

\section{Results}

Establishment of a whole-cell system for the conversion of cholesterol and analogs using Bacillus megaterium

In order to provide $B$. megaterium with the ability to perform the side-chain cleavage reaction on steroids, we transformed protoplasts of the strain MS941 (DSMZ: German Collection of Microorganisms and Cell Cultures) with the tricistronic vector pSMF2.1_SCCAA. This plasmid contains an operon consisting of genes for bovine CYP11A1 as well as its natural redox partners Adx and AdR under the control of a xylose-inducible promoter (Fig. 1a). Three model substrates were chosen for a potential whole-cell conversion with this recombinant strain: the zoosterols cholesterol and 7-dehydrocholesterol (7-DHC) as well as the phytosterol $\beta$-sitosterol (Fig. 1b-d, insets). All steroids were dissolved in an aqueous solution of 2-hydroxypropyl- $\beta$-cyclodextrin and Quillaja saponin. Simultaneous to protein induction, the substrate solution was added to the shake-flask cultivated recombinant $B$. megaterium strain. As assessed by RP-HPLC, remarkably high pregnenolone and 7-dehydropregnenolone yields of $95 \mathrm{mg} \mathrm{L}^{-1} 48 \mathrm{~h}^{-1}$ could be achieved when using cholesterol or 7-DHC, respectively (Fig. 1b, c), which corresponds to a conversion of approximately $116 \mathrm{mg} \mathrm{L}^{-1} 48 \mathrm{~h}^{-1}(300 \mu \mathrm{M})$ of these substrates (Fig. 1f). The phytosterol $\beta$-sitosterol was converted to a lesser extent (Fig. 1d), with a conversion rate of $25 \mathrm{mg} \mathrm{L}^{-1}$ $48 \mathrm{~h}^{-1}$ (Fig. 1f). As illustrated in Fig. 1e, the addition of
Quillaja saponin to the culture with a final concentration of $0.2 \%$ drastically increased the cholesterol conversion rate by $250 \%$, demonstrating a new application of these naturally occurring surface-active glycosides for the permeabilization of bacterial membranes for steroidal compounds. The untransformed host strain MS941 was not able to metabolize cholesterol (Additional file 1: Figure S1). Whole-cell produced pregnenolone and 7-dehydropregnenolone were purified by preparative RP-HPLC and their structures confirmed by NMR spectroscopy against authentic standards.

\section{Identification of PHB bodies as main catalytic sites in recombinant $B$. megaterium}

To evaluate the localization of the recombinantly produced proteins as well as the substrate in the cells of $B$. megaterium, we conducted confocal laser scanning microscopic (CLSM) studies. Firstly, fusion genes of either cyp11A1, $a d x$ and $a d r$ with egfp were constructed via SOE-PCR and cloned into vector pSMF2.1. Bacillus megaterium strain MS941 was transformed with the resulting plasmids pSMF2.1_CYP11A1eGFP, pSMF2.1_ AdxeGFP or pSMF2.1_AdReGFP (Additional file 1: Figures S1-S3). Figures $2 \mathrm{a}-\mathrm{c}$ illustrate the localization of the fusion proteins in the cells. To visualize a potential membrane localization of the recombinant proteins, an additional counterstaining with the fluorescent dye FM 4-64 [26] was carried out, which interacts with the polar phosphate groups of the outer leaflet of plasma membranes. While Adx exhibited a cytosolic distribution (Fig. 2c), the naturally membrane-associated proteins CYP11A1 and AdR were localized to distinct structures spread throughout the cells (Fig. 2a, b), which had a similar appearance to the PHB-bodies, monolayer coated hydrophobic aggregates of bioplastic serving as carbon storage, which can be specifically stained with the oxazone dye Nile red [27]. The cultivation of B. megaterium in TB-medium resulted in sufficient PHB granule formation for microscopic studies (Fig. 2d). Subsequently, fusion protein expressing strains were stained with Nile red. As shown in Fig. 2e, f, CYP11A1eGFP and AdReGFP localized to the PHB granules, providing evidence that both membrane proteins autonomously associate with these structure, without the addition of affinity tags to the proteins' sequence. In contrast, the fusion between the soluble Adx and eGFP exhibited a cytosolic distribution and no association with the PHB granules (Fig. 2g).

To follow the fate of the substrate, we incubated cells of $B$. megaterium MS941 with the fluorescent cholesterol analog 25-[N-[(7-nitro-2-1,3-benzoxadiazol-4-yl)methyl] amino]-27-norcholesterol (25-NBD cholesterol) [28]. Again, this probe associated with the cells' PHB granules (Fig. 2h), indicating that the substrate as well as the 

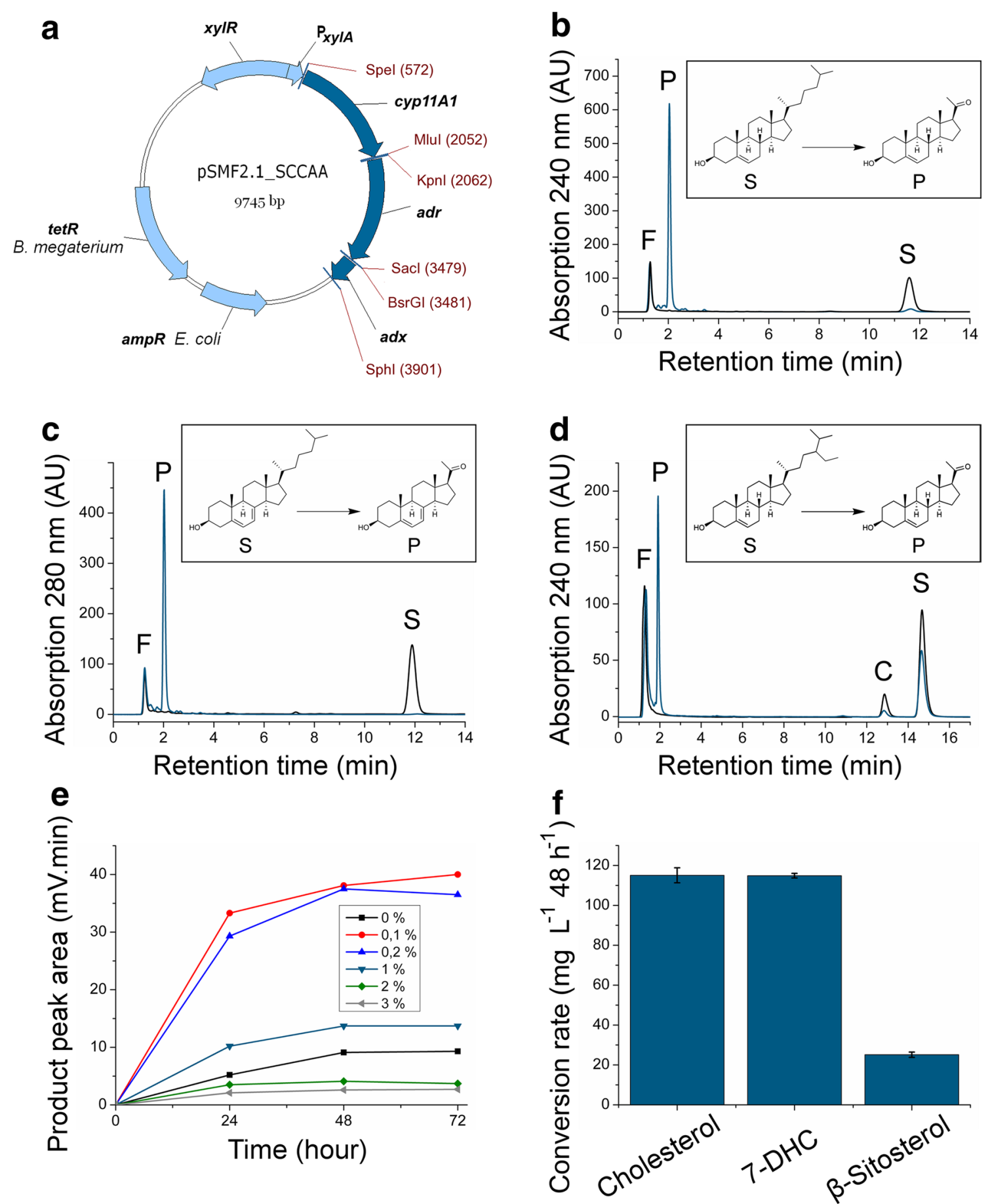

Fig. 1 Characterization of B. megaterium (strain MS941) whole-cell system for the conversion of cholesterol and analogs. a Tricistronic vector pSMF2.1_SCCAA encoding side-chain cleavage enzyme CYP11A1 as well as redox partners AdR and Adx under the control of a xylose-inducible promoter $\left(P_{x y} \mid A\right.$, promoter xylose utilization operon; xylR, xylose repressor; tet $R$, tetracycline resistance gene; ampR, ampicillin resistance gene). $\mathbf{b}$ HPLC-chromatograms of the conversion of cholesterol after $48 \mathrm{~h}$ (light gray strain MS941 transformed with pSMF2.1_SCCAA, black untransformed strain, $S$ cholesterol, $P$ pregnenolone, $F$ flow-through peak). c HPLC-chromatograms of the conversion of 7-DHC after $48 \mathrm{~h}$ (light gray strain MS941 transformed with pSMF2.1_SCCAA, black untransformed strain, S7-DHC, P 7-DHP, F flow-through peak). d HPLC chromatograms of the conversion of $\beta$-sitosterol after $48 \mathrm{~h}$ (light gray strain MS941 transformed with pSMF2.1_SCCAA, black untransformed strain, $S \beta$-sitosterol, $P$ pregnenolone, $C$ campesterol contained in the sample as minor impurity, $F$ flow-through peak). e Effect of different final concentrations of Quillaja saponin (inset) on product yield. The substrate was dissolved in a 45\% 2-hydroxypropyl- $\beta$-cyclodextrin with varying saponin concentrations and added to the cultures directly after protein induction. Pregnenolone yield after cholesterol conversion was determined by HPLC. $\mathbf{f}$ Conversion rates of substrates cholesterol, 7-DHC and $\beta$-sitosterol after $48 \mathrm{~h}$. Error bars indicate standard deviation of triplicate biological experiments. 

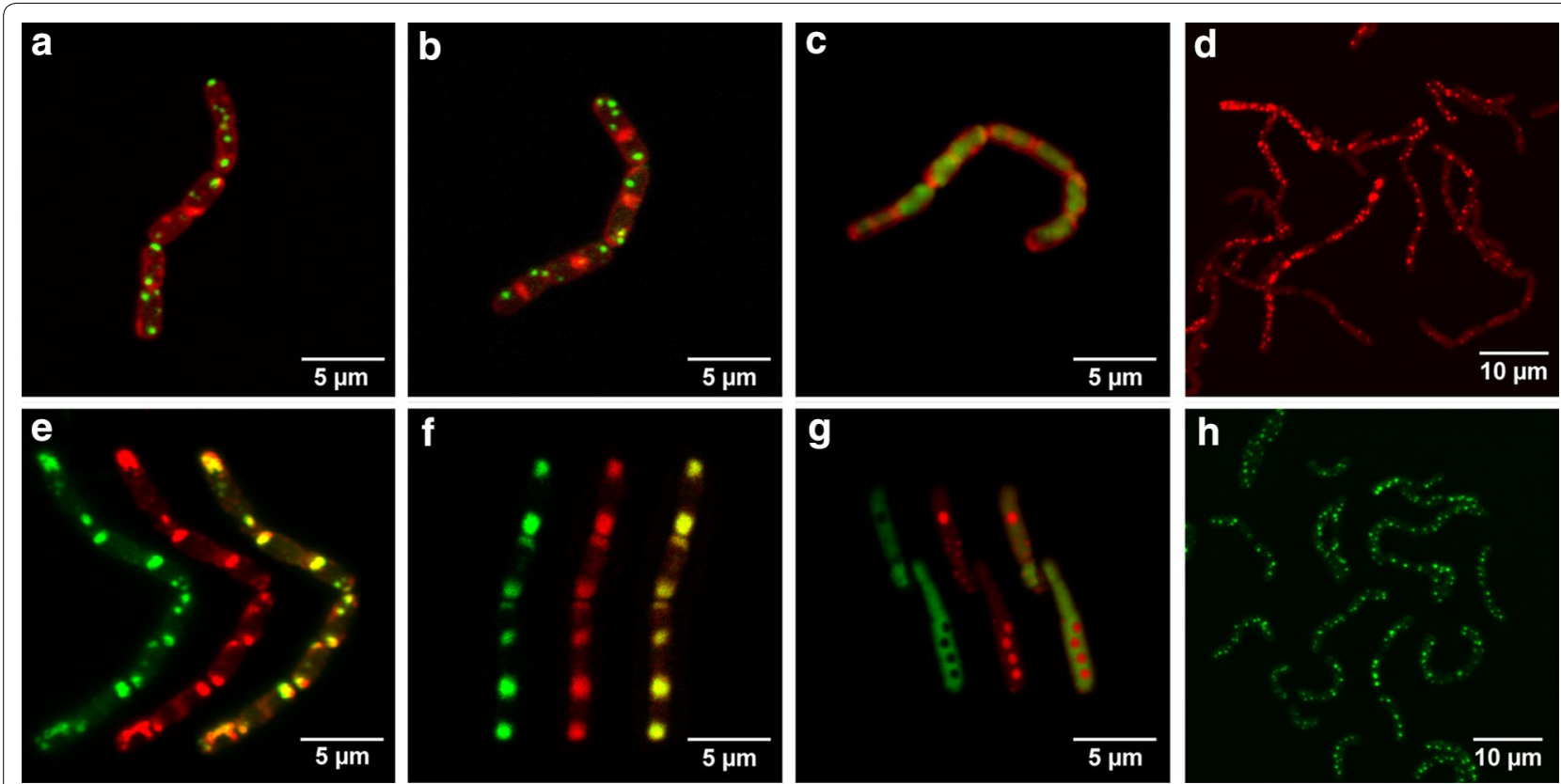

Fig. 2 Localization of eGFP fused CYP11A1, AdR and Adx as well as 25-NBD cholesterol in cells of B. megaterium strain MS941 analyzed by confocal fluorescence microscopy. a-c CYP11A1eGFP, AdReGFP and AdxeGFP expressing cells, respectively, counterstained with FM 4-64. CYP11A1eGFP and AdReGFP form aggregates, while AdxeGFP is expressed in a soluble form. $\mathbf{d}$ Staining of untransformed cells with PHB specific dye Nile red. e- $\mathbf{g}$ Nile red staining of cells expressing CYP11A1eGFP, AdReGFP and AdxeGFP, respectively (merged images). From left to right: eGFP emission signal, Nile red emission signal, and overlay, showing overlapping signals in yellow. CYP11A1eGFP and AdReGFP are localized at the PHB granules, while AdxeGFP is present solely in the cytosol. h 25-NBD cholesterol accumulated in PHB bodies of cells. The number of single cells attached to one another via their peptidoglycane layer differs, leading to differently sized cell aggregates.

membrane proteins CYP11A1 and AdR are localized to these storage compounds.

\section{Deletion of PHA polymerase subunit PhaC: effect on cholesterol storage, PHB accumulation and in vivo conversion}

In order to assess the role of the PHB-bodies in catalyzing the whole-cell conversion of steroids in recombinant $B$. megaterium in more detail, we aimed to delete the gene encoding the PHA polymerase subunit $\mathrm{PhaC}[29]$ to eliminate the formation of PHB-granules.

In B. megaterium, deletion of genes can be achieved by transforming cells with a plasmid containing flanking regions of the target gene [30]. Two homologous recombination events with each flanking region are required to replace the target gene with the deletion construct (Fig. 3). Replication of the knockout plasmid can be prevented by cultivating cells at a non-permissive temperature, based on a temperature-sensitive origin of replication contained in this plasmid (Fig. 4a, b). However, this method alone proved to be inefficient for the deletion of phaC, since it resulted only in colonies still containing the full-length target gene. Therefore, a counter-selection system was established, based on a previously described method for Bacillus subtilis, making use of the uracil phosphoribosyltransferase (upp) gene [31]. The upp gene allows selection for cells that no longer possess the plasmid after the knockout procedure and are thus not sensitive to the highly toxic antimetabolite 5-fluorouracil (5-FU). Since B. megaterium MS941 naturally possesses this gene, at first a gene deletion mutant of this strain had to be created. Flanking regions of upp were cloned into the temperature-sensitive origin of replication-harboring vector pUCTV2 [30]. Cells of $B$. megaterium strain MS941 were transformed with the resulting vector pUCTV2_ $\Delta u p p$ and underwent the knockout procedure, as described in the "Methods" section. A colony was selected that was still able to grow on 5-FU containing agar. The deletion of the genomic upp ORF was confirmed by PCR (Fig. 4c) and the resulting strain was designated as GHH1. Then, flanking regions of the PHA polymerase subunit phaC were cloned into the vector pUCTV2_Upp containing the intact upp gene. Strain GHH1 was transformed with the resulting plasmid pUCTV2_Upp_ $\Delta$ phaC. The deletion of the phaC ORF was successfully verified by utilizing a combination of the Upp-counterselection and a PCR-screening (Fig. 4d). The resulting strain was designated as GHH3.

Cells of strain GHH3 stained with Nile red completely lacked PHB accumulation (compare Fig. 5a with Fig. 2d). 


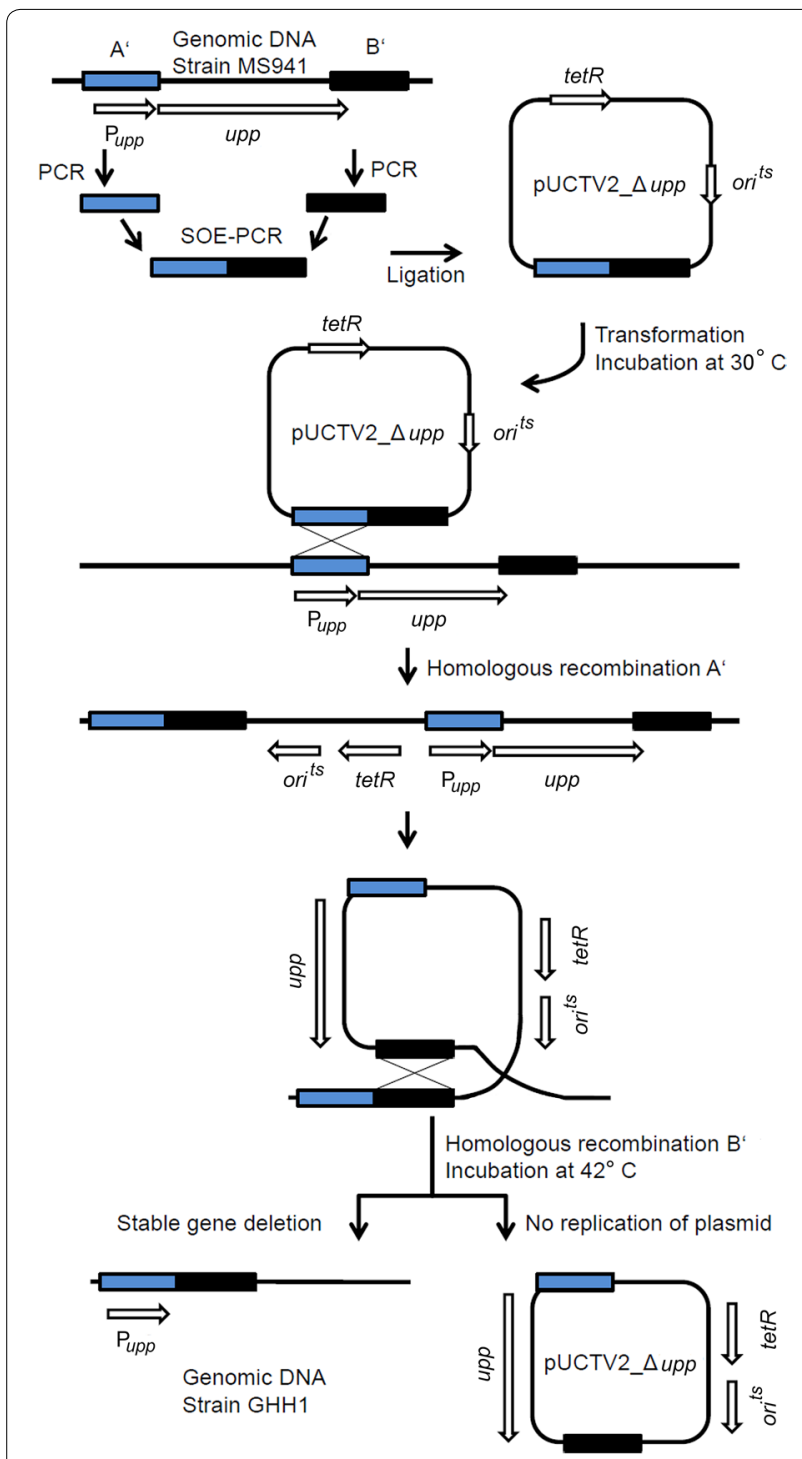

Fig. 3 Schematic representation of upp deletion. Flanking genomic regions $A^{\prime}$ and $B^{\prime}$ of the target gene were amplified and fused via SOE-PCR. The resulting deletion construct was cloned into vector pUCTV2. Bacillus megaterium was transformed with the resulting plasmid pUCTV2__upp and cultivated at $30^{\circ} \mathrm{C}$. After two subsequent recombination events with each homologous fragment the deletion of upp was obtained. Incubation at the non-permissive temperature prevents replication of the plasmid containing the intact copy of the upp gene $\left(\mathrm{ori}^{\text {ts }}\right.$, temperature-sensitive origin of replication; $P_{\text {upp }}$, promoter uracil phosphoribosyltransferase; tet $R$, tetracycline resistance gene; upp, uracil phosphoribosyltransferase gene).

To exclude a possible unspecific gene deletion that could lead to an absence of $\mathrm{PHB}$ production, cells of strain GHH3 were transformed with plasmid pSMF3_RBCP (Additional file 1: Figure S5), encoding the genes of the PHB-synthesis operon: PHA polymerase subunit phaR, acetoacetyl-CoA reductase phaB, polyhydroxyalkanoic acid inclusion protein phaP and the genomically deleted gene phaC. As expected, the chromosomal deletion of phac was complemented, resulting in a restored $\mathrm{PHB}$ production (Fig. 5b).

The new strain GHH3 was transformed with pSMF2.1_ CYP11A1eGFP. Surprisingly, the Nile red-stained cells of GHH3 expressing CYP11A1eGFP (Fig. 5c) displayed a similar distribution of the fusion protein in the bacterium compared with the PHB-producing strain GHH1 (Fig. 2e). We then expressed a fusion protein between eGFP and B. megaterium's phasin phaP (Additional file 1: Figure S6), an amphiphilic protein associated with the PHB bodies' monolayer, to assess whether the distribution of CYP11A1eGFP in strain GHH3 is an artifact stemming from the heterologous origin of the protein. As displayed in Fig. 5d, e, similar to CYP11A1eGFP, phaPeGFP exhibited an indistinguishable distribution in GHH1 and GHH3, both stained with Nile red, irrespective of $\mathrm{PHB}$ production.

As the disabled $\mathrm{PHB}$ production of the strain had no apparent effect on the overexpression of CYP11A1, we subsequently incubated strain GHH3 with the substrate analog 25-NBD cholesterol. The microscopic analysis revealed that the cells had lost the ability to store the sterol when no PHB was present (Fig. 5f).

Lastly, we investigated whether the impaired substrate storage in absence of $\mathrm{PHB}$ in $B$. megaterium cells has an effect on the in vivo whole-cell cholesterol conversion rate. We compared strain GHH3 with GHH1 and pSMF3_RBCP-containing GHH3, each one being transformed with pSMF2.1_SCCAA, encoding the genes for CYP11A1, Adx and AdR. Figure 6 illustrates the pregnenolone yield for each strain normalized to the cell dry weight, to exclude a potential effect of the gene deletion on the growth of $B$. megaterium cells. The absence of PHB in cells of GHH3 led to no detectable product formation after $24 \mathrm{~h}$ and an $88 \%$ decreased pregnenolone yield after $48 \mathrm{~h}$ compared with GHH1. The capacity to convert cholesterol was partly restored in strain GHH3 transformed with the complementing PhaC encoding plasmid pSMF3_RBCP.

\section{Discussion}

With an annual worldwide production exceeding $1,000,000$ tons, steroid drugs are the second most marketed medical agents next to antibiotics [32]. The biotechnological steroid production is one of the best examples of the successful combination of microbial conversions and chemical reaction steps [1], since some specific modifications of the steroid skeleton cannot be performed by the latter. Examples of such reactions are stereo- and regioselective hydroxylations, dehydrogenations, and the steroid side-chain cleavage presented in 

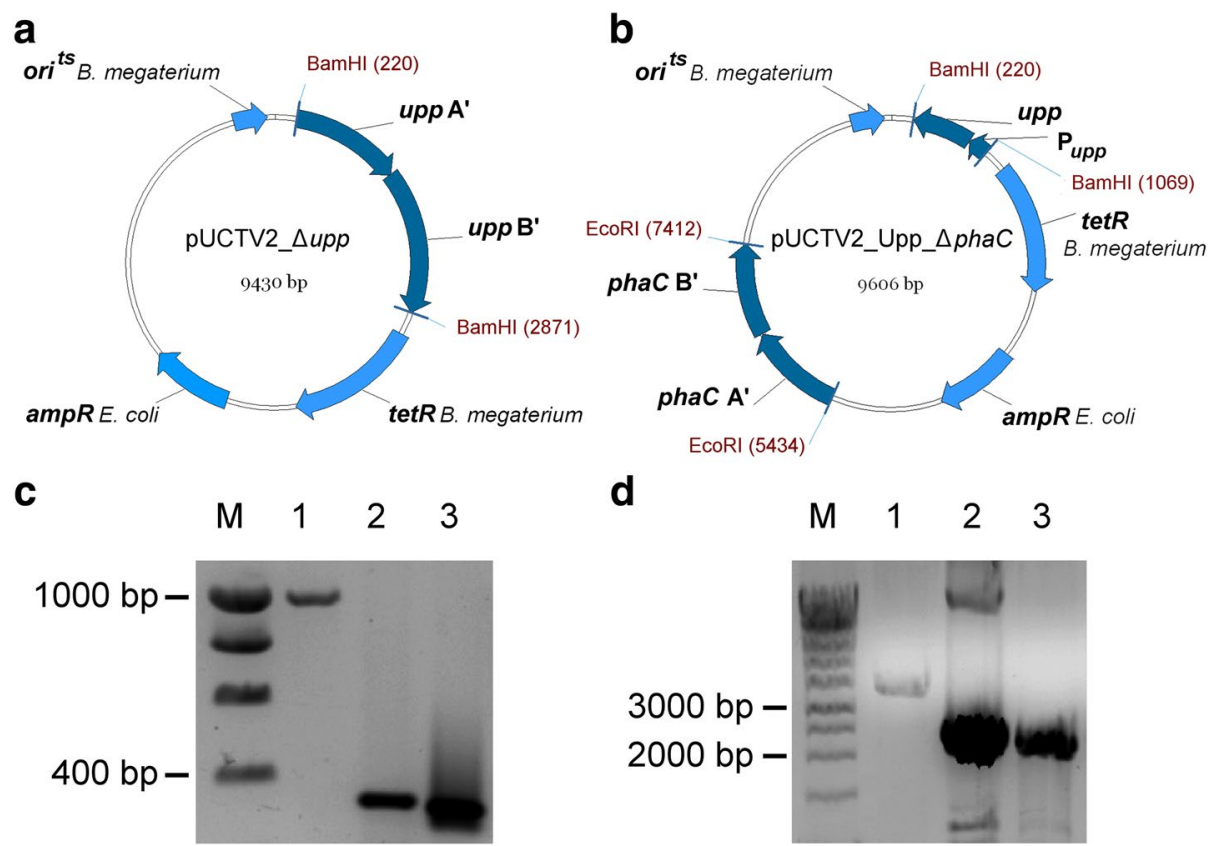

d

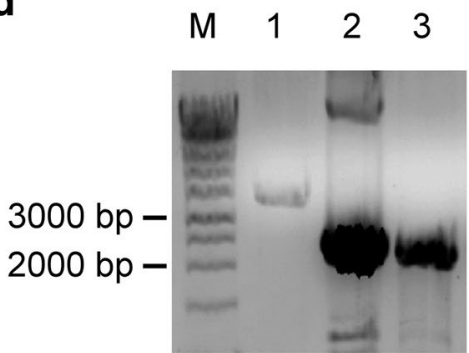

Fig. 4 Deletion of the counterselection marker upp and the PHA polymerase subunit gene phaC. a Vector pUCTV2_ $\Delta$ upp for the deletion of upp, containing flanking genomic regions upstream and downstream of the gene (upp $A^{\prime}$ and upp $B^{\prime}$ ). The temperature-sensitive origin of replication $\left(\mathrm{or}^{\text {ts }}\right)$ prevents replication of the plasmid above temperatures of $42^{\circ} \mathrm{C}$ (tet $R$, tetracycline resistance gene; ampR, ampicillin resistance gene). $\mathbf{b}$ Vector pUCTV2_Upp__phaC for the deletion of phaC, containing flanking genomic regions upstream and downstream of the gene (phaC $\mathrm{A}^{\prime}$ and phaC $\mathrm{B}^{\prime}$ ). It additionally contains the gene for the uracil phosphoribosyltransferase (upp) under the control of its natural promoter $\left(\mathrm{P}_{\text {upp }}\right)$ which serves as a counterselection marker. c Agarose gel showing the PCR products using primers 9 and 10, flanking the upp gene and its promoter. Amplification with these primers results in DNA fragments of $865 \mathrm{bp}$ size, if the upp-ORF is intact. The following templates were used: genomic DNA of MS941 (lane 1), pUCTV2_ $\triangle$ upp (lane 2) and genomic DNA of upp deletion strain GHH1 (lane 3). The resulting fragment contained the upp gene truncated by 600 bp (lane 3) compared to the full-length gene (lane 1) (lane M: smartladder DNA marker (Eurogentec). d Agarose gel showing the PCR products using flanking primers 11 and 14. These bind approximately 1,000 bp upstream and downstram of the target gene. Amplification with these primers results in DNA fragments of ca. 3,000 bp size, if the phaC-ORF is intact. The following templates were used: genomic DNA of strain GHH1 (lane 1), pUCTV2_Upp__phaC (lane 2) and genomic DNA of strain GHH3 (lane 3). The resulting fragment contained the phaC gene truncated by $1,088 \mathrm{bp}$ (lane 3) compared to the full-length fragment (lane 1) (lane M: smartladder DNA marker). Additional bands in lane 2 stem from the plasmid used as DNA template.

this paper. Although there are many microorganisms of different taxa, which are able to convert cholesterol or phytosterols to androstenedione, androstadienedione or other C19-steroids, the efficient microbial conversion of these substrates to pregnenolone has not been described so far $[33,34]$. The most abundant steroid in vertebrates, cholesterol, can be obtained in huge amounts by extraction of wool grease or bovine spinal cords [35].

In this study we developed a recombinant whole-cell catalyst that efficiently cleaves the side-chain of sterols, converting the substrates cholesterol and $\beta$-sitosterol to pregnenolone, and 7-dehydrocholesterol to 7-dehydropregnenolone. In order to perform these reactions, the Gram-positive bacterium B. megaterium strain MS941 served as a host for the expression of the bovine sidechain cleavage enzyme CYP11A1 and its redox partners Adx and AdR under control of the inducible strong xylose promoter. The resulting recombinant strain converted each of the three substrates in our study to one specific product (Fig. 1b-d). NMR-spectroscopy confirmed that the expected products pregnenolone or 7-dehydropregnenolone were formed with no visible side-product formation. The addition of Quillaja saponin, a mixture of amphiphilic glycosides obtained from the 'soap bark tree' Quillaja saponaria [36] greatly improved the sterol conversion rate (Fig. 1e). It has been demonstrated before that these compounds increase cholesterol solubility in aqueous solutions by micelle formation [37] and are able to form pores in biological membranes in complex with cholesterol [38]. We propose that saponins can facilitate the transport of cholesterol into the whole-cell system of B. megaterium without having detrimental effects on the cells, since cultures were still able to grow and convert cholesterol up to $48 \mathrm{~h}$ after addition of the additive 

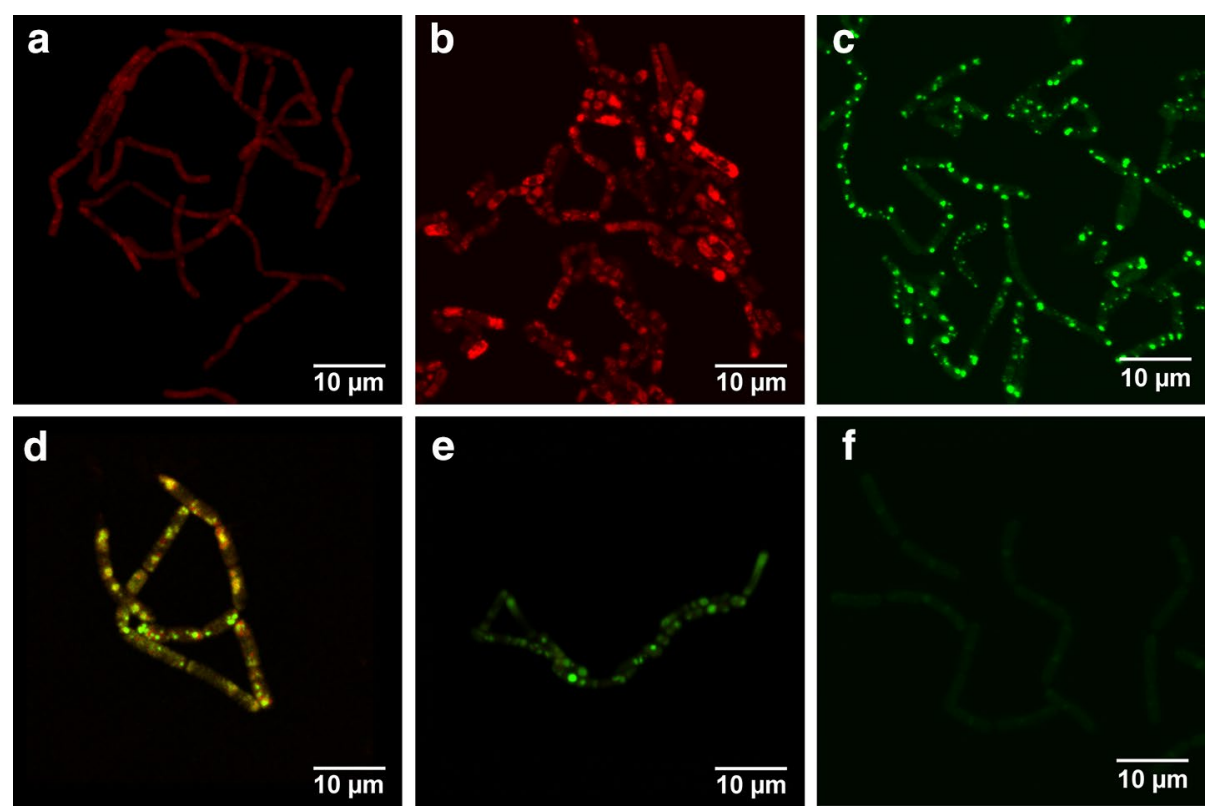

Fig. 5 Effect of PHA polymerase subunit phaC knockout on morphology of strain GHH3. a Nile red stained $\Delta$ phaC strain GHH3 exhibits no accumulation of PHB. b PHB production is restored in cells after transformation with phaC containing plasmid pSMF3_RBCP. c Strain GHH3 transformed with pSMF2.1_CYP11A1eGFP. Expressed CYP11A1eGFP forms aggregates in the cell. d, e Expression of phaPeGFP in GHH1 and GHH3, respectively, both stained with Nile red (overlay). f Fluorescent probe 25-NBD cholesterol is not stored in cells of strain GHH3 lacking PHB.

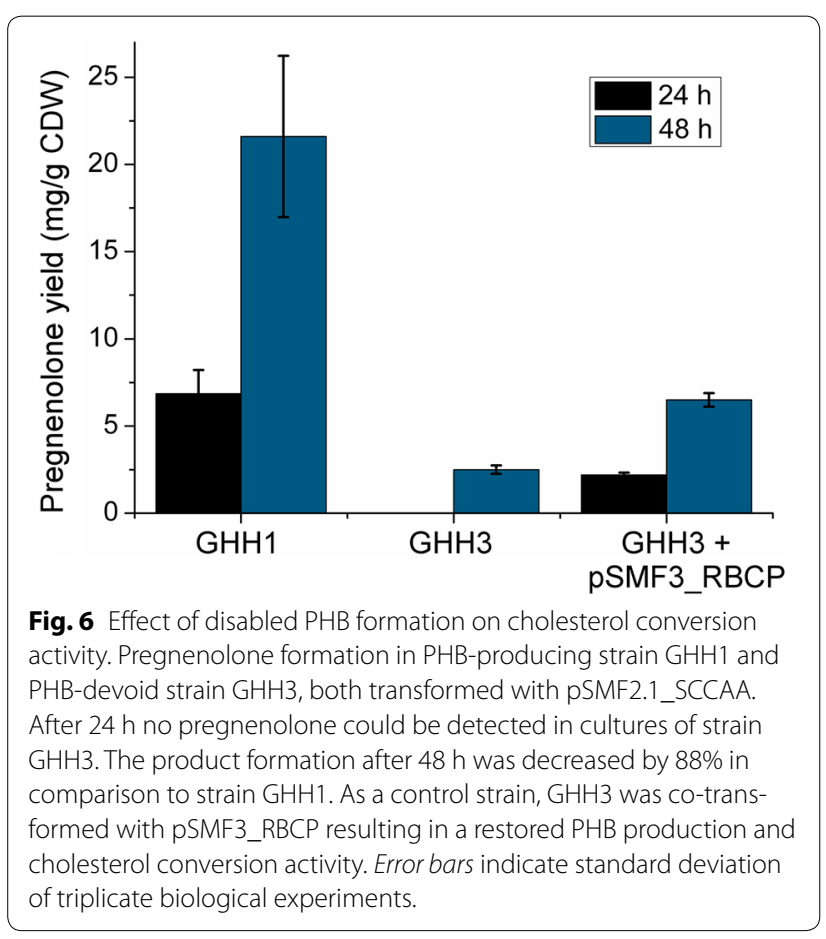

in the early exponential phase, while maintaining their morphological integrity. Once the concentration of the additive was optimized (Fig. 1e), $300 \mu \mathrm{M}$ of cholesterol were completely converted to pregnenolone in $48 \mathrm{~h}$. These values have been reached under simple discontinous shake-flask cultivation and already exceed the pregnenolone concentration described for high-cell density cultivation of recombinant S. cerevisae $\left(\sim 60 \mu \mathrm{M} 48 \mathrm{~h}^{-1}\right.$; [6]). Comparable systems for pregnenolone production do not exist. 7-DHC was converted with an equal rate, while $\beta$-sitosterol conversion was considerably lesser (Fig. 1f). The reduced conversion rate of the latter is in congruence with published experiments using a reconstituted system containing purified CYP11A1, AdR and Adx displaying a $66 \%$ lower turnover number (kcat) of CYP11A1 for $\beta$-sitosterol (and 46\% for campesterol) compared with cholesterol [39]. This may be attributed to the more branched side-chain of $\beta$-sitosterol, which possibly slows down its entry into the active site of CYP11A1 and its movement during the three-step side-chain cleavage reaction. Site-directed mutagenesis of the CYP11A1 gene to generate a protein providing more space for the bulky substrate might solve this problem in the future.

In order to elucidate the macromolecular basis for the efficient transfer and conversion of these hydrophobic substrates in $B$. megaterium, we firstly analyzed the localization of the recombinant proteins. B. megaterium strains were generated producing $C$-terminally tagged eGFP fusion proteins of CYP11A1, AdR and Adx. CLSM analysis revealed that AdxeGFP was localized in the 
cytosol (Fig. 2g). This is in accordance with its function as a soluble protein shuttle, transferring electrons from AdR to CYP11A1. Surprisingly, CYP11A1 and AdR were shown to be localized at the PHB granules (Fig. 2e, f), as demonstrated by Nile red staining.

PHB granules accumulate in the bacterium upon excessive carbon supply in the medium and can be mobilized as a source of energy when carbon is limited [40]. The granules' surface appears to provide an optimal environment for the functional association of the mammalian membrane proteins CYP11A1 and AdR. Although this result was unexpected, the principle association to a phospholipid monolayer is in accordance with their nature as membrane proteins.

We further investigated the localization of the substrate in cells of $B$. megaterium utlizing the fluorescent analog 25-NBD cholesterol. As in the case of AdReGFP and CYP11A1eGFP, the probe accumulated in the PHB granules (Fig. 2h). Concluding from these findings, we proposed that $B$. megaterium can efficiently take up the substrate under the applied biotransformation conditions and that the highly hydrophobic core of the PHB granules is able to store cholesterol, which is subsequently converted by CYP11A1, associated with the surrounding monolayer.

To provide further evidence for this assumption, we aimed to disable the PHB granule production by deleting the large PHA polymerase subunit encoding gene phaC, applying a new counter-selection system for $B$. megaterium. The resulting strain GHH3 was unable to produce $\mathrm{PHB}$, as demonstrated by Nile red staining. The PHB production could be restored by transforming this strain with a plasmid encoding the PHB operon including $p h a C$, although the shape of the cells and granula differed from the wild type strain GHH1, possibly due to the overexpression of the PHB granules-synthesizing proteins and the increased PHB accumulation.

Contrary to our expectation that CYP11A1 tagged with eGFP would now be localized at the bacterium's membrane, the fusion protein expressed in the PHB-devoid strain GHH3 still exhibited a similar aggregation pattern compared with strain GHH1, although no PHB granules should be present in the cells (Fig. 5c; cross-sections through cells of both strains are displayed in Additional file 1: Figure S7). According to the three existing models, activity of the PHA polymerase is necessary for the biogenesis of PHB granules in microorganisms [41-43]: the 'micelle' model suggests that PHB is produced in the cytosol and the monolayer coats the PHB when a certain size is reached, the 'budding' model states that PHB is produced in the intermembrane space, leading to a budding off the membrane and lastly the 'scaffold' model proposes that the PHB synthesis is initiated from the bacterial nucleoid, to which the required proteins are attached. We repeated the localization experiment overexpressing B. megaterium's chromosomally encoded phasin phaP, a natural main constituent of the PHB granules' monolayer responsible for size regulation, to assess whether the aggregation of CYP11A1eGFP is an artificial effect due to the protein's heterologous nature. However, similar to CYP11A1eGFP, phasineGFP was expressed in aggregates in both GHH1 and GHH3 (Fig. 5d, e). It remains to be elucidated if the observed protein structures are 'hollow' PHB bodies, proteinaceous inclusion bodies or self-oligomerized protein complexes, e.g. by investigating the localization of other naturally PHB monolayer associated proteins. Self-oligomerization of the eGFP tag can be excluded, since AdxeGFP exhibits a cytosolic distribution.

In contrast to the CYP11A1 expression, accumulation of the cholesterol analog 25-NBD cholesterol inside the cells of PHB-lacking strain GHH3 was not observed, indicating that substrate storage and uptake is the crucial factor for the efficiency of the whole-cell system (Fig. 5f).

To substantiate this finding, the in vivo cholesterol conversion activity with strains GHH1and GHH3 expressing CYP11A1 and its redox partners was assessed (Fig. 6). The pregnenolone yield for the PHB-devoid strain was drastically decreased, but could be increased again after complementing the PHB formation in strain GHH3 by co-transformation with a plasmid encoding the PHB synthesis operon. Pregnenolone levels did not reach those of strain GHH1, which could be explained by lower expression levels of CYP11A1, Adx and AdR, as well as decreased NADPH availability due to the overexpression of the PHB synthesizing operon. In conclusion, the strongly impaired substrate storage observed by fluorescence microscopy is in congruence with the diminished cholesterol conversion rate in B. megaterium cells lacking PHB production.

Overall, our results provide evidence that the efficient conversion of cholesterol in the recombinant $B$. megaterium whole-cell system is based on the natural ability of the microorganism to form subcellular scaffolds in form of PHB granules. The core of these granules serves as storage for hydrophobic sterols, whereas the surface layer can host mammalian membrane proteins in an active form. This system was applied for the conversion of the hydrophobic substrates cholesterol and $\beta$-sitosterol to pregnenolone and 7-dehydrocholesterol to 7-dehydropregnenolone, both pharmaceutically interesting starting compounds for further steroid hormone production, by the side-chain cleaving cytochrome P450 CYP11A1. Taken together, B. megaterium is a particularly promising host for the expression of further cholesterol-metabolizing membrane proteins such as CYP27A1, CYP3A4 
or CYP46A1 for biotechnological applications or the elucidation of new products. In addition, it could generally serve as an expression platform for membrane proteins, such as microsomal Cytochromes P450 and be suitable for the bioconversion of hydrophobic substrates with an affinity for the PHA synthesized by this bacterium.

\section{Conclusion}

Cholesterol is the precursor molecule of all steroid hormones, encompassing glucocorticoids, mineralocorticoids and sex steroids. Due to its extremely low solubility in water, an efficient microbial conversion has not been possible so far. In the present paper we describe a wholecell system based on the soil bacterium $B$. megaterium, which, by recombinantly expressing the side-chain cleaving cytochrome P450 CYP11A1 and its redoxpartners, is able to efficiently convert cholesterol to pregenenolone, the central compound of steroidogenesis. We demonstrate that the microorganism's PHB granules, aggregates of bioplastic coated with a protein/phospholipid monolayer, are crucial for the high conversion rate by serving as substrate storage. Furthermore, we provide evidence that the natural membrane proteins CYP11A1 and its redox partner AdR are attached to the granules' monolayer, implying that these structures can host eukaryotic membrane proteins in a properly folded state (Fig. 7). This microbial system allows the targeted microbial

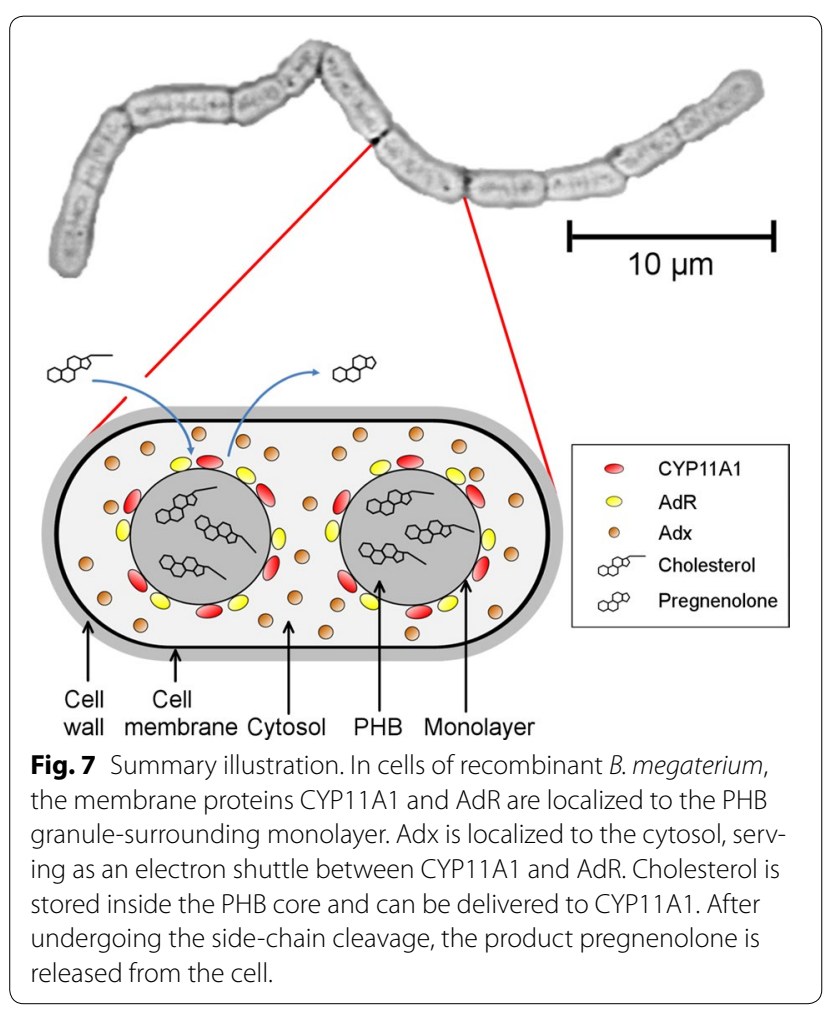

production of steroid hormones starting from the abundantly available substrate cholesterol or analogs.

\section{Methods}

\section{Molecular cloning}

Sequences of the bovine genes encoding mature CYP11A1 (mutant K193E [44] based on NCBI Reference Sequence: NP_788817.1), AdR (NP_777116.1) and Adx (NP_851354.1) were codon-optimized for B. megaterium (http://www.jcat.de) and synthesized by Geneart AG (Regensburg, Germany). The resulting genes were cloned into shuttle vector pSMF2.1 [45] by using SpeI/MluI, $\mathrm{KpnI} / \mathrm{SacI}$ and BsrGI/SphI restriction sites, respectively, resulting in plasmid pSMF2.1_SCCAA. All three genes are located in an operon under the control of the strong inducible promoter $\mathrm{P}_{x y l A}$. Each gene contains its own ribosomal binding site. In $E$. coli, the $ß$-lactamase is produced, conferring ampicillin resistance. In B. megaterium, the tetracycline efflux pump is produced, conferring tetracycline resistance. Plasmids pSMF2.1_CYP11A1eGFP, pSMF2.1_AdReGFP and pSMF2.1_AdxeGFP encoding CYP11A1, AdR and Adx with a C-terminally fused eGFP tag (Additional file 1: Figures S2-S4) were constructed by SOE-PCR using the respective primers $2 \mathrm{a} / 3 \mathrm{a}, 2 \mathrm{~b} / 3 \mathrm{~b}$ and $2 \mathrm{c} / 3 \mathrm{c}$ in combination with primers 1 and 4 and pSMF2.1_SCCAA and pEGFP-C1 (clontech) as templates. The resulting fused genes were cloned into pSMF2.1 with restrictions sites SpeI and MluI. The fusion gene encoding phaPeGFP (Additional file 1: Figure S6) was constructed by SOE-PCR using primers 21-24 with genomic $B$. megaterium DNA pEGFP-C1 (clontech) as templates. The resulting fragment was cloned into pSMF2.1 using PacI and SpeI restriction site resulting in vector pSMF2.1_phaPeGFP. Vector pUCTV2__upp was constructed by cloning flanking regions $\mathrm{A}^{\prime}$ and $\mathrm{B}^{\prime}$ into vector pUCTV2 via BamHI sites. The deletion construct was created by SOE-PCR using genomic DNA of $B$. megaterium strain MS941 as template and primers 5, 6, 7 and 8. Vector pUCTV2_Upp__phaC was constructed by cloning the full-length upp gene and its natural promoter into pUCTV2 using a BamHI site, after amplifying the fragment by PCR using genomic DNA of B. megaterium strain MS941 and primers 9 and 10. The deletion construct containing A' and B' was amplified and fused by SOE-PCR using genomic DNA as template and primers 11,12, 13 and 14, then ligated into plasmid pUCTV2 Upp via the EcoRI restriction site. Vector pSMF3_RBCP was constructed by ligating two PCR fragments sequentially into the vector pMGBm19 [46] via the restriction sites XhoI, MluI and SacI. The first fragment comprising the operon of phaR, phaB and phaC under control of the natural promoter $\mathrm{P}_{\text {phaR }}$ and the second fragment comprising the phaP gene were amplified using genomic 
DNA of B. megaterium strain MS941 and primers 15,16 , 17 and 18 resulting in the new operon $\mathrm{P}_{\text {phaR }}$-phaR-phaBphaC-phaP (Additional file 1: Figure S5).

Sequences of all primers are listed in Additional file 1: Table S1. Strains and plasmids used in this study are listed in Additional file 1: Tables S2, S3. All cloning experiments were performed with E. coli strain Top10 (Invitrogen). Plasmids were prepared using Nucleospin Plasmid QuickPure kit (Macherey \& Nagel). Genomic DNA was extracted by Genomic DNA Extraction kit (nexttec). Ligations were carried out using FastLink DNA Ligase kit (Epicentre Biotechnologies). All restriction enzymes were purchased from New England Biolabs. Bacillus megaterium cells were transformed according to the PEG-mediated protoplast transformation method [47].

\section{B. megaterium cultivation conditions}

Either LB- (25 g/L, Becton-Dickinson) or TB- $(24 \mathrm{~g} / \mathrm{L}$ yeast extract, $12 \mathrm{~g} / \mathrm{L}$ tryptone, $0.4 \%$ glycerol, $100 \mathrm{mM}$ potassium phosphate buffer, $\mathrm{pH}$ 7.4) media were used for the cultivation of $B$. megaterium. For the preculture, $50 \mathrm{~mL}$ of medium either containing $10 \mu \mathrm{g} / \mathrm{mL}$ tetracycline (cells harboring a variant of pSMF2.1) or $10 \mu \mathrm{g} / \mathrm{mL}$ chloramphenicol (cells harboring a variant of pSMF3) were inoculated with cells from an agar plate or glycerol stock. For the main culture, $50 \mathrm{~mL}$ of medium containing $10 \mu \mathrm{g} / \mathrm{mL}$ of the required antibiotic were inoculated with $500 \mu \mathrm{L}$ of the preculture. The main culture was grown until an optical density of $\sim 0.4$ was reached, protein expression was induced by addition of $0.25 \mathrm{~g}$ xylose dissolved in $1 \mathrm{~mL}$ distilled water. For whole-cell conversion experiments, substrates were dissolved in a $45 \%$ 2-hydroxypropyl- $\beta$-cyclodextrin/4\% Quillaja saponinsolution. $2.5 \mathrm{~mL}$ of the solution were added to the culture directly after protein induction. A final substrate concentration of $300 \mu \mathrm{M}$ was used for all conversion experiments. Cholesterol from sheep wool (purity $\geq 99 \%$ ), 7-dehydrocholesterol ( $\geq 98 \%), \beta$-sitosterol from plant extracts (purity $\geq 70 \%$, containing residual campesterol), 2-hydroxypropyl- $\beta$-cyclodextrin (average molecular weight $\sim 1,460$ ) and Quillaja saponin (Sapogenin content $\geq 10 \%$ ) were purchased from Sigma-Aldrich.

\section{Sample treatment and RP-HPLC analysis}

Steroids without intrinsic absorption were converted into their $\Delta_{4}$-3-keto-derivatives prior to RP-HPLC analysis, to allow photometric detection at $240 \mathrm{~nm} .1 \mathrm{~mL}$ culture samples were boiled in water for $1 \mathrm{~min} .20 \mu \mathrm{L}$ cholesterol oxidase solution ( $5 \mathrm{mg}$ cholesterol oxidase (Calbiochem) and $5 \mathrm{mg} \mathrm{Na}$-cholate dissolved in $5 \mathrm{~mL} 50 \mathrm{mM}$ HEPES buffer $\mathrm{pH} 7$, containing $0.05 \%$ Tween-20) were added and the sample was incubated at $37^{\circ} \mathrm{C}$ with $1,000 \mathrm{rpm}$ shaking for $1 \mathrm{~h}$. For RP-HPLC analysis, the sample was extracted twice with $1 \mathrm{~mL}$ ethylacetate and the extract was dissolved in acetonitrile. Samples were analyzed isocratically with pure acetonitrile using a NUCLEODUR 100-3 $\mathrm{C}_{18}$ column (Macherey \& Nagel). Samples containing cholestenone and $\beta$-sitostenone were detected at $240 \mathrm{~nm}$ wavelength, 7-DHC at $280 \mathrm{~nm}$. A flow rate of $1 \mathrm{~mL} / \mathrm{min}$ was applied. Progesterone yield was calculated by using a progesterone calibration curve. 7-Dehydropregnenolone yield was determined by dividing product peak area by total substrate/product peak area. To purify pregnenolone for NMR analysis after whole-cell conversion, $200 \mathrm{~mL}$ culture medium were extracted and separated using a $250 / 8$ NUCLEODUR $100-3 C_{18}$ column and the product collected.

\section{Cell staining and confocal fluorescence microscopy}

Bacillus megaterium was cultivated under the same conditions as for the in vivo conversion experiments. Prior to staining, culture samples were washed and centrifuged twice to diminish background fluorescence. $20 \mu \mathrm{L}$ of cell suspension were spread on coverslips and fixed by air drying. For Nile red (Sigma-Aldrich) staining, drops of a solution of $1 \mathrm{mg} / \mathrm{mL}$ Nile red dissolved in ethanol were added to the coverslips, incubated for $10 \mathrm{~s}$ and rinsed with ethanol. For FM 4-64 (Invitrogen) staining drops of a solution of $1 \mathrm{mg} / \mathrm{mL}$ FM 4-64 dissolved in distilled water were added to the coverslips, incubated for $10 \mathrm{~s}$ and rinsed with water. Samples were analyzed with a LSM 510 confocal microscope (Zeiss). Excitation and emission maxima for eGFP, Nile red and FM 4-64 are as follows (in nm): 488/509, 552/636 and 558/734. Cells were magnified $1,000 \times$ using immersion oil and digitally zoomed in, if necessary.

\section{Gene deletion in B. megaterium}

To delete the upp gene, $B$. megaterium MS941 was transformed with the plasmid pUCTV2__upp containing the deletion construct. $50 \mathrm{~mL}$ LB medium containing $10 \mu \mathrm{g} /$ $\mathrm{mL}$ tetracycline were inoculated with transformed colonies and incubated at $30^{\circ} \mathrm{C}$ and $180 \mathrm{rpm}$ for $16 \mathrm{~h}$. Culture samples were diluted 1:10 and spread out on minimal medium agar plates, based on modified Spizizen's salts [48], and incubated at $30^{\circ} \mathrm{C}$ for $16 \mathrm{~h}$. Colonies were then replica plated and incubated at $42^{\circ} \mathrm{C}$ for $16 \mathrm{~h}$. Colonies containing a genomic deletion of the upp gene were able to grow on minimal agar plates containing $1 \mu \mathrm{M}$ 5-FU. The truncation of the gene was verified by PCR, using primers 9 and 10. The resulting strain was named GHH1. The phaC gene was knocked out by transforming cells of strain GHH1 with plasmid pUCTV2_Upp_sphaC. $50 \mathrm{~mL} \mathrm{LB}$ medium containing $10 \mu \mathrm{g} / \mathrm{mL}$ tetracycline were inoculated with transformed colonies and incubated at $30^{\circ} \mathrm{C}$ and $180 \mathrm{rpm}$ for $16 \mathrm{~h}$. Culture samples were 
diluted 1:10, spread out on minimal medium agar plates and incubated at $30^{\circ} \mathrm{C}$ for $16 \mathrm{~h}$. Colonies were replica plated on minimal agar plates containing $1 \mu \mathrm{M} 5$-FU and incubated at $42^{\circ} \mathrm{C}$ for $16 \mathrm{~h}$. The resulting grown colonies either contained the full-length or truncated form of the phaC gene. Absence of PHB production was confirmed by Nile red staining and the gene deletion verified by PCR using primers 11 and 14 . The resulting strain was designated as GHH3.

\section{Additional file}

Additional file 1. Supplemental data containing plasmid maps, list of primers and strains and additional results.

\section{Authors' contributions}

F.H., R. Bernhardt and A.G. designed research; A.G. performed research; M.K. and R. Biedendieck provided reagents or plasmids; F.H., R.B. and A.G. analyzed data; and A.G. and F.H. wrote the paper. All authors read and approved the final manuscript.

\section{Author details}

${ }^{1}$ Centre for Human and Molecular Biology, Institute of Biochemistry, Saarland University, 66123 Saarbrücken, Germany. ${ }^{2}$ Institute of Microbiology, Technische Universität Braunschweig, 38106 Braunschweig, Germany.

\section{Acknowledgements}

We would like to thank Josef Zapp for performing NMR analysis of purified substrates, Leon Muijs for introducing us to the CLSM and Elmar Krause (SFB 894, platform project nanoscopy) for microscopy support, Friedhelm Meinhardt (Münster) for providing plasmid pUCTV2, Julia Nikolaus for providing GFP fusion constructs and Matthias Bureik for proof-reading of the manuscript.

\section{Compliance with ethical guidelines}

\section{Competing interests}

AG., M.K., R. Bernhardt and F.H. are listed as inventors on a PCT application, assigned by Sanofi SA, covering the whole-cell system described in this publication.

Received: 12 June 2015 Accepted: 21 July 2015

Published online: 29 July 2015

\section{References}

1. Murakami M, Ito Y (1999) Cleavage of carbon-carbon single bonds by transition metals. In: Murai S, Alper H, Gossage RA, Grushin WV, Hidai M, Ito $Y$ et al (eds) Activation of unreactive bonds and organic synthesis. topics in organometallic chemistry. Springer, Berlin Heidelberg, pp 97-129

2. Schiffler B, Kiefer M, Wilken A, Hannemann F, Adolph HW, Bernhardt R (2001) The interaction of bovine adrenodoxin with CYP11A1 (cytochrome P450scc) and CYP11B1 (cytochrome P45011 beta). Acceleration of reduction and substrate conversion by site-directed mutagenesis of adrenodoxin. J Biol Chem 276(39):36225-36232

3. Tong WY, Dong X (2009) Microbial biotransformation: recent developments on steroid drugs. Recent Pat Biotechnol 3(2):141-153

4. Hirschmann R (1992) The cortisone era: aspects of its impact. Some contributions of the Merck Laboratories. Steroids 57(12):579-592

5. Makeeva DS, Dovbnya DV, Donova MV, Novikova LA (2013) Functional reconstruction of bovine P450scc steroidogenic system in Escherichia coli. Am J Mol Biol 3:173-182

6. Duport C, Spagnoli R, Degryse E, Pompon D (1998) Self-sufficient biosynthesis of pregnenolone and progesterone in engineered yeast. Nat Biotechnol 16(2):186-189
7. Szczebara FM, Chandelier C, Villeret C, Masurel A, Bourot S, Duport C et al (2003) Total biosynthesis of hydrocortisone from a simple carbon source in yeast. Nat Biotechnol 21(2):143-149

8. Dumas B, Brocard-Masson C, Assemat-Lebrun K, Achstetter T (2006) Hydrocortisone made in yeast: metabolic engineering turns a unicellular microorganism into a drug-synthesizing factory. Biotechnol J 1(3):299-307

9. Slominski A, Semak I, Zjawiony J, Wortsman J, Gandy MN, Li J et al (2005) Enzymatic metabolism of ergosterol by cytochrome p450scc to biologically active 17alpha,24-dihydroxyergosterol. Chem Biol 12(8):931-939

10. Bunk B, Schulz A, Stammen S, Munch R, Warren MJ, Rohde M et al (2010) A short story about a big magic bug. Bioeng Bugs. 1(2):85-91

11. Vary PS, Biedendieck R, Fuerch T, Meinhardt F, Rohde M, Deckwer WD et al (2007) Bacillus megaterium-from simple soil bacterium to industrial protein production host. Appl Microbiol Biotechnol 76(5):957-967

12. Grinberg AV, Hannemann F, Schiffler B, Muller J, Heinemann U, Bernhardt R (2000) Adrenodoxin: structure, stability, and electron transfer properties. Proteins. 40(4):590-612

13. Bernhardt R (2006) Cytochromes P450 as versatile biocatalysts. J Biotechnol 124(1):128-145

14. Sono M, Roach MP, Coulter ED, Dawson JH (1996) Heme-containing oxygenases. Chem Rev 96(7):2841-2888

15. Hannemann F, Bichet A, Ewen KM, Bernhardt R (2007) Cytochrome P450 systems-biological variations of electron transport chains. Biochim Biophys Acta 1770(3):330-344

16. Weng JH, Liang MR, Chen CH, Tong SK, Huang TC, Lee SP et al (2013) Pregnenolone activates CLIP-170 to promote microtubule growth and cell migration. Nat Chem Biol 9(10):636-642

17. Slominski AT, Zmijewski MA, Semak I, Zbytek B, Pisarchik A, Li W et al (2014) Cytochromes p450 and skin cancer: role of local endocrine pathways. Anti-Cancer Agents Med Chem 14(1):77-96

18. Lemoigne M (1926) Produits de l'hydration et de polymerisation de l'acide $\beta$-oxobutyrique. Bull Soc Chem Biol (Paris) 8:770-782

19. Griebel R, Smith Z, Merrick JM (1968) Metabolism of poly-beta-hydroxybutyrate. I. Purification, composition, and properties of native poly-betahydroxybutyrate granules from Bacillus megaterium. Biochemistry 7(10):3676-3681

20. McCool GJ, Fernandez T, Li N, Cannon MC (1996) Polyhydroxyalkanoate inclusion-body growth and proliferation in Bacillus megaterium. FEMS Microbiol Lett 138(1):41-48

21. Jendrossek D (2009) Polyhydroxyalkanoate granules are complex subcellular organelles (carbonosomes). J Bacteriol 191(10):3195-3202

22. Grage K, Jahns AC, Parlane N, Palanisamy R, Rasiah IA, Atwood JA et al (2009) Bacterial polyhydroxyalkanoate granules: biogenesis, structure, and potential use as nano-/micro-beads in biotechnological and biomedical applications. Biomacromolecules 10(4):660-669

23. Potter M, Steinbüchel A (2005) Poly(3-hydroxybutyrate) granuleassociated proteins: impacts on poly(3-hydroxybutyrate) synthesis and degradation. Biomacromolecules 6(2):552-560

24. Rehm BH, Steinbuchel A (1999) Biochemical and genetic analysis of PHA synthases and other proteins required for PHA synthesis. Int I Biol Macromol 25(1-3):3-19

25. Rehm BH (2007) Biogenesis of microbial polyhydroxyalkanoate granules: a platform technology for the production of tailor-made bioparticles. Curr Issues Mol Biol. 9(1):41-62

26. Vida TA, Emr SD (1995) A new vital stain for visualizing vacuolar membrane dynamics and endocytosis in yeast. J Cell Biol 128(5):779-792

27. Kranz RG, Gabbert KK, Madigan MT (1997) Positive selection systems for discovery of novel polyester biosynthesis genes based on fatty acid detoxification. Appl Environ Microbiol 63(8):3010-3013

28. Ostasov P, Sykora J, Brejchova J, Olzynska A, Hof M, Svoboda P (2013) FLIM studies of 22- and 25-NBD-cholesterol in living HEK293 cells: plasma membrane change induced by cholesterol depletion. Chem Phys Lipids 167-168:62-69

29. McCool GJ, Cannon MC (2001) PhaC and PhaR are required for polyhydroxyalkanoic acid synthase activity in Bacillus megaterium. J Bacteriol 183(14):4235-4243

30. Wittchen KD, Meinhardt F (1995) Inactivation of the major extracellular protease from Bacillus megaterium DSM319 by gene replacement. Appl Microbiol Biotechnol 42(6):871-877 
31. Fabret C, Ehrlich SD, Noirot P (2002) A new mutation delivery system for genome-scale approaches in Bacillus subtilis. Mol Microbiol 46(1):25-36

32. Bureik M, Bernhardt R (2007) Steroid hydroxylation: microbial steroid biotransformations using cytochrome P450 enzymes. Modern biooxidation. Wiley-VCH Verlag GmbH \& Co. KGaA, Weinheim, pp 155-176

33. Fernandes P, Cruz A, Angelova B, Pinheiro HM, Cabral JMS (2003) Microbial conversion of steroid compounds: recent developments. Enzyme Microb Technol 32(6):688-705

34. Donova MV, Egorova OV (2012) Microbial steroid transformations: current state and prospects. Appl Microbiol Biotechnol 94(6):1423-1447

35. O'Neil MJ (2001) The Merck Index_an encyclopedia of chemicals, drugs, and biologicals, 13th edn. Merck \& Co., Whitehouse Station, p 381

36. Francis G, Kerem Z, Makkar HP, Becker K (2002) The biological action of saponins in animal systems: a review. Br J Nutr 88(6):587-605

37. Mitra S, Dungan SR (2001) Cholesterol solubilization in aqueous micellar solutions of quillaja saponin, bile salts, or nonionic surfactants. J Agric Food Chem 49(1):384-394

38. Hassan SM, Byrd JA, Cartwright AL, Bailey CA (2010) Hemolytic and antimicrobial activities differ among saponin-rich extracts from guar, quillaja, yucca, and soybean. Appl Biochem Biotechnol 162(4):1008-1017

39. Tuckey RC, Cameron KJ (1993) Side-chain specificities of human and bovine cytochromes P-450scc. Eur J Biochem/FEBS 217(1):209-215

40. Handrick R, Reinhardt S, Jendrossek D (2000) Mobilization of poly(3hydroxybutyrate) in Ralstonia eutropha. J Bacteriol 182(20):5916-5918

41. Stubbe J, Tian J (2003) Polyhydroxyalkanoate (PHA) hemeostasis: the role of PHA synthase. Nat Product Rep 20(5):445-457
42. Lacapere JJ, Pebay-Peyroula E, Neumann JM, Etchebest C (2007) Determining membrane protein structures: still a challenge! Trends Biochem Sci 32(6):259-270

43. Jendrossek D, Pfeiffer D (2014) New insights in the formation of polyhydroxyalkanoate granules (carbonosomes) and novel functions of poly(3hydroxybutyrate). Environ Microbiol 16(8):2357-2373

44. Janocha S, Bichet A, Zollner A, Bernhardt R (2011) Substitution of lysine with glutamic acid at position 193 in bovine CYP11A1 significantly affects protein oligomerization and solubility but not enzymatic activity. Biochim Biophys Acta 1814(1):126-131. doi:10.1016/j.bbapap.2010.06.002

45. Bleif S, Hannemann F, Zapp J, Hartmann D, Jauch J, Bernhardt R (2012) A new Bacillus megaterium whole-cell catalyst for the hydroxylation of the pentacyclic triterpene 11-keto-beta-boswellic acid (KBA) based on a recombinant cytochrome P450 system. Appl Microbiol Biotechnol 93(3):1135-1146

46. Gamer M, Frode D, Biedendieck R, Stammen S, Jahn D (2009) A T7 RNA polymerase-dependent gene expression system for Bacillus megaterium. Appl Microbiol Biotechnol 82(6):1195-1203. doi:10.1007/ s00253-009-1952-5

47. Biedendieck R, Borgmeier C, Bunk B, Stammen S, Scherling C, Meinhardt F et al (2011) Systems biology of recombinant protein production using Bacillus megaterium. Methods Enzymol 500:165-195

48. Saxild HH, Nygaard P (1987) Genetic and physiological characterization of Bacillus subtilis mutants resistant to purine analogs. J Bacteriol 169(7):2977-2983

\section{Submit your next manuscript to BioMed Central and take full advantage of:}

- Convenient online submission

- Thorough peer review

- No space constraints or color figure charges

- Immediate publication on acceptance

- Inclusion in PubMed, CAS, Scopus and Google Scholar

- Research which is freely available for redistribution

Submit your manuscript at

www.biomedcentral.com/submit

C BioMed Central 